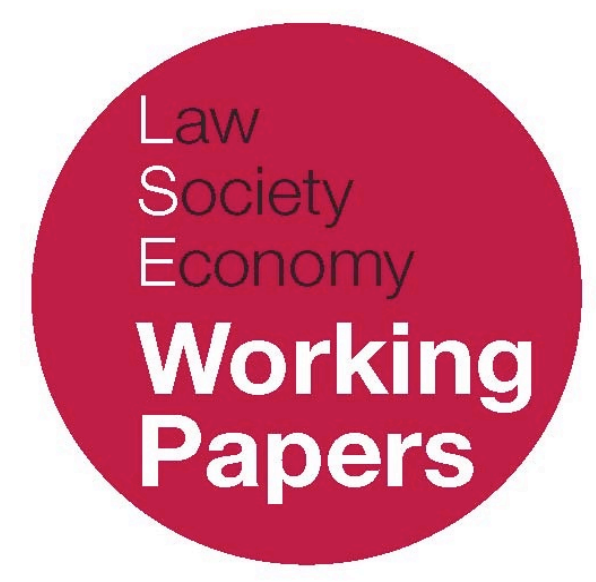

\title{
The Proportionality of Lockdowns
}

\author{
forthcoming in \\ Aleida Mendes Borges, Sinéad Murphy, Yossi Nehushtan, and Peter Sutoris \\ (eds.), Pandemic Response and the Cost of Lockdowns: Global Debates from Humanities \\ and Social Sciences (Routledge, 2022)
}

\section{Kai Möller}

LSE Law, Society and Economy Working Papers 13/2021

London School of Economics and Political Science

Law School

This paper can be downloaded without charge from LSE Law, Society and Economy Working Papers at: www.lse.ac.uk/collections/law/wps/wps.htm and the Social Sciences Research Network electronic library at: https://ssrn.com/abstract $=3973261$.

(C) Kai Möller. Users may download and/or print one copy to facilitate their private study or for non-commercial research. Users may not engage in further distribution of this material or use it for any profit-making activities or any other form of commercial gain. 


\title{
The Proportionality of Lockdowns
}

\author{
Kai Möller*
}

\begin{abstract}
Proportionality is the test used by courts in the liberal-democratic world to determine the justifiability and legitimacy of repressive state measures. This chapter considers whether the lockdowns imposed in the context of the Covid-19 pandemic were proportionate and thus legally and morally justifiable. It points out three pathologies of the political and public discourse around lockdowns, all of which relate to the final stage of the test, which examines the appropriateness of the balance struck between the severity of the restriction on freedom and the public interest in protecting health and lives. First, by focusing in a one-sided way on the protection of life, the public and political discourse neglected the question of the severity of the restriction on freedom and, relatedly, the costs of lockdowns, in particular their social, medical, psychological, cultural, and economic costs. Second, by de facto placing a taboo on the question of the relevance of the age distribution of the people dying from Covid-19, a proper consideration of this relevant factor was prevented. Third, the considerations that were regarded as determinative in striking the balance between protecting life and guaranteeing freedom, namely the protection of the health services from being overburdened and/or giving preference to human life as the highest value, were normatively unconvincing. Because of the complexity of, in particular, the empirical questions, this chapter cannot reach a confident conclusion as to the proportionality of the recent lockdowns. It does, however, show that the public and political discourse was biased in favour of lockdowns and offers a doctrinal structure as well as normative reflection on how to conduct the proportionality assessment properly.
\end{abstract}

\footnotetext{
* Professor of Law, Law School, London School of Economics and Political Science. Email: k.moller@1se.ac.uk. I would like to thank Mattias Kumm, Jo Murkens, Yossi Nehushtan, Peter Ramsay, and Paul Yowell for helpful discussions and valuable comments on previous drafts.
} 


\section{INTRODUCTION}

Lockdowns are repressive state measures that severely restrict individual freedom and rights and are therefore constitutionally suspect. The legal and constitutional standard that courts around the world rely on to assess the justifiability and legitimacy of such measures is the principle of proportionality. This chapter examines whether the lockdowns imposed in response to the Covid-19 pandemic in 2020 and 2021 were proportionate and therefore legitimate. It points out which questions a court assessing the proportionality of lockdowns would have to ask and develops normative standards with regard to some of the relevant issues.

At the core of the issue is the question of the acceptable balance between what we might call 'the protection of life and health' and 'freedom'. I will argue that the balance struck by most states was affected by a number of biases in favour of imposing lockdowns. First, by focusing in a one-sided way on the protection of health and lives, the public and political discourse neglected the question of the severity of the restriction on freedom and, relatedly, the costs of lockdowns, in particular their social, medical, psychological, cultural, and economic costs. Second, by de facto placing a taboo on the question of the relevance of the age distribution of the people dying from Covid 19, a proper consideration of this relevant factor was prevented. Third, the considerations that were regarded as determinative in striking the balance, namely the protection of the health services from being overburdened and/or giving preference to human life as the highest value, were normatively unconvincing. Because of the complexity of, in particular, the empirical questions relating to the costs of lockdowns, this chapter cannot reach a confident conclusion as to the proportionality of the recent lockdowns. It does, however, show that the public and political discourse was biased in favour of lockdowns and offers a doctrinal structure as well as normative reflection on how to conduct the proportionality assessment properly.

\section{PROPORTIONALITY}

The standard of review that courts around the world use to assess the justifiability of repressive state measures is called 'the principle of proportionality', or simply 'proportionality'. Proportionality requires the state measures to pursue a legitimate goal, to be a suitable means of achieving the goal, to be necessary in that there must not exist a less restrictive but equally effective alternative, and to be 'proportionate in the strict sense', the establishing of which requires a balancing exercise between the severity of the restriction and the importance of the public interest pursued. ${ }^{1}$ Proportionality was first developed by the Prussian administrative courts to review the exercise of police powers in the context of administrative law. It has since then quickly spread from administrative to

${ }^{1}$ See, for example, Kai Möller, The Global Model of Constitutional Rights (Oxford University Press, 2012, paperback 2015), 13-14. 
constitutional as well as EU and international law and from Prussia and Germany to many parts of the liberal democratic world. ${ }^{2}$

There has been a wide-ranging debate about the principle of proportionality in recent years. The view that has emerged from this is that the point of proportionality review is to ensure that an act which burdens a person is reasonably justifiable to bim or her; a judicial system that is committed to this idea is sometimes referred to as endorsing a 'culture of justification' 3 or as giving effect to each person's 'right to justification'. ${ }^{4}$ Thus, if a state imposes a repressive measure such as a lockdown, an affected citizen might ask: 'How dare you limit my liberty? What's your justification for this?'. And our citizen might not only ask this question but also take the case to court. The court's job will then be to assess whether the lockdown is reasonably justifiable. The test that courts use to establish this is proportionality. If the court reaches the conclusion that the measure is disproportionate not reasonably justifiable - and therefore in violation of the citizen's right to justification, it will make a declaration to this effect or strike it down (depending on the specifics of the legal system).

For our purposes, it is important to note two points. First, the legitimacy of repressive state measures is not only a political and/or moral question but also a legal and constitutional one. A state that restricts our liberty must have a sufficient justification for doing so, and policing this is the proper role of the courts, which apply the principle of proportionality to fulfil their task. Second, the considerations that courts rely on when assessing the proportionality of a repressive measure are not different in character from the considerations that politicians, journalists, or ordinary citizens utilise when assessing various actual or proposed policies. The law does not require any 'secret knowledge' accessible only to the initiated in this regard. Proportionality is simply a structure that allows judges to engage in the practical reasoning required to assess the justifiability of a policy. The fact that, as will be shown, well into the second year of this pandemic, we have no, or only clearly deficient, answers to some of the basic questions that proportionality directs us to examine shows that something has gone seriously wrong with our democratic deliberation of this crucially important issue.

\section{LOCKDOWNS AND PROPORTIONALITY}

\section{Legitimate GOAL, SUITABILITY AND NECESSITY}

The recent lockdowns passed the first three stages of the proportionality test relatively smoothly. First, regarding the legitimate goal stage, lockdowns were imposed for a clearly legitimate goal, namely to protect people's lives (preventing death) and health

\footnotetext{
2 Moshe Cohen-Eliya and Iddo Porat, Proportionality and Constitutional Culture (Cambridge University Press, 2013), ch. 2 .

${ }^{3}$ The term was coined by Etinenne Mureinik, 'A Bridge to Where? Introducing the Interim Bill of Rights', 10 (1994) South African Journal on Human Rights 31, 32. For more detailed analysis, see Cohen-Eliya and Porat (above n 2), ch. 6; Kai Möller, 'Justifying the Culture of Justification', 17 (2019) International Journal of Constitutional Law 1078.

${ }^{4}$ Mattias Kumm, 'The Idea of Socratic Contestation and the Right to Justification: The Point of Rights-Based Proportionality Review', 4 (2010) Law \& Ethics of Human Rights 141.
} 
(preventing, in particular, severe courses of Covid-19 and what has come to be called 'long Covid').

Second, they were also a suitable means for achieving this goal because they plausibly achieved the reduction of social contacts and therefore opportunities for spreading the virus. There seems to be some disagreement on this point because in some cases, lockdowns were imposed when infection numbers were already declining; hence the case could be made that any subsequent reduction in infection rates was the result of other factors. This may or may not be empirically true; nevertheless, the link between limiting or reducing the number of social contacts and reducing infections with a virus that is spread through social contact is plausible. Hence, it is also plausible to assume that lockdowns will have led to a reduction in numbers of people getting infected with the virus and therefore also to a reduction in numbers of people dying of it or developing long Covid. This is sufficient in the context of this stage of the test.

The third question is whether lockdowns were necessary in that there was no less restrictive but equally effective alternative. Critics of lockdowns often point to the 'Swedish way' of dealing with the pandemic, which focused less on legal prohibitions and more on recommendations, or the approach advocated by the Great Barrington Declaration, which proposed 'shielded protection' of those most at risk from the virus but otherwise no restrictions, in order to build up herd immunity which would then also protect the vulnerable. ${ }^{5}$ But whether these approaches really are equally effective is empirically unclear. For example, the proponents of the 'Swedish way' tend to compare the number of Covid deaths in Sweden with those in other European countries, its opponents with those in the other Scandinavian countries. There are empirical uncertainties here partly because it is difficult to compare the effectiveness of one country's approach with that of another country or a hypothetical alternative (as in the case of the Great Barrington Declaration, which, to my knowledge, has not been followed anywhere). Where there is empirical uncertainty, proportionality grants the original decision maker (the state) a certain margin of appreciation. Note also that it would seem that lockdowns work quite well precisely because they are such extreme measures. Connected to this point, the strongest argument in favour of the 'Swedish approach' and the Great Barrington Declaration seem to be not that they are necessarily (or demonstrably) better at protecting lives and health but rather that they strike a more appropriate balance between freedom and protecting lives; this is however not a question to be considered at the necessity stage but rather at the balancing stage.

At this point a qualification is in order and a limitation of this paper has to be stated. The real question with regard to how to respond to the Covid-19 pandemic was not a 'yes/no' decision as to whether or not to impose lockdowns. Rather, there is a sliding scale of measures reaching from letting the virus rip through society, to an approach broadly following the 'Swedish way', to a 'soft' lockdown, and then towards a strict lockdown and a 'No Covid' policy. A properly conducted proportionality assessment would therefore

5 https://gbdeclaration.org/. 
have to assess the lockdown chosen by the state relative to the other possible responses. ${ }^{6}$ Furthermore, the individual measures which in their totality amount to a lockdown would have to be examined individually, such as school closures, curfews, closure of shops, prohibitions on visiting the inhabitants of care homes, and so on. This paper, perhaps crudely, glosses over those questions and chooses a simpler structure in order to focus our attention on the more basic normative questions that proportionality directs us to investigate.

\section{BALANCING}

This takes us to the fourth stage, the balancing stage, and here the substantive problems lurk. Remember that the proportionality test requires the establishment of three things at this stage: first, the severity of the interference with freedom (thus: in particular, the burdens that the respective lockdown imposes on people's ability to freely live their lives); second, the importance of the competing public interest (the importance of protecting health and lives); third, the relationship between the two (to determine whether the importance of the public interest in protecting health and lives outweighs the severity of the restriction on freedom). ${ }^{7}$ Each of these issues raises difficult questions, and none of them was satisfactorily addressed in public and political discourse at the time.

\section{a. The severity of the restriction}

Let us start with the first question. Lockdowns are indisputably extremely severe restrictions on personal freedom. The principle of proportionality as well as common sense require that a government contemplating the imposition of a measure as drastic as a lockdown must assess very carefully not only what the desired and likely positive effects of such a measure might be (more on that below) but also what the likely collateral damage caused by this social intervention for people's freedom - in the terminology of human and constitutional rights law: their ability to 'freely develop their personality' ${ }^{-}$- will be. This requires the government to engage in a comprehensive impact assessment before imposing the lockdown, and it further requires that this assessment be kept under review for the duration of the lockdown to ensure that its continuation is justified.

The harms of lockdowns to freedom are considerable. Humans are social beings and social contact is necessary for our flourishing. The limitation of social contact imposes a considerable burden on virtually everyone's ability to flourish and freely develop his or her personality. The outer symptoms of such deprivation will often be loneliness and under-stimulation and in more severe cases depression, anxiety, or substance abuse; in the

\footnotetext{
${ }^{6}$ On the question of how to deal with a range of possible policies at the necessity stage of the proportionality test, see David Bilchitz, 'Necessity and Proportionality: Towards a Balanced Approach', in Lazarus, McCrudden, and Bowles (eds), Reasoning Rights: Comparative Judicial Engagement (Hart, 2016), ch. 3.

${ }^{7}$ On the three sub-questions to be analysed at the balancing stage, see Robert Alexy, A Theory of Constitutional Rights (Oxford University Press, 2002), 401.

8 Article 2 (1) of the German Basic Law begins: 'Everyone has the right to freely develop his personality .... The Universal Declaration of Human Rights mentions the idea of the (free) development of one's personality three times (in Articles 22, 26, and 29). The idea is also often referred to by the European Court of Human Rights, particularly in the context of Article 8 of the European Convention on Human Rights (the right to respect for private and family life).
} 
most extreme cases it may lead to suicide. Lockdowns that involve school and university closures pose a particularly grave burden on children and students by hindering their education and their ability to develop skills and competence - important both for themselves as well as society - and their broader personal development. The outer symptoms will, again, often be loneliness, isolation, and poor mental health. ${ }^{9}$ Lack of in person contact with, in particular, teachers and physicians makes it harder to spot signs of abuse, the likelihood of which will also be increased during lockdowns in light of the intense stress this creates for many parents and carers; in general, the data suggests that domestic violence has risen during the lockdowns. ${ }^{10}$ The restrictions that lockdowns have brought for many old people and in particular the inhabitants of care homes - who often suffer from isolation and, relatedly, poor mental health even during normal times - are perhaps in the region of what we would ordinarily consider to be inhuman. ${ }^{11}$

Lockdowns further have grave economic consequences and in particular have led and will lead to the closure of a large number of businesses, imposing severe burdens on their owners and employees who may face unemployment together with its associated negative consequences for individual well-being. ${ }^{12}$ Similar considerations apply to the lives and careers of artists and others working in the cultural sector. The enormous debts that governments have accumulated to deal with the pandemic and the consequences of the lockdowns will undoubtedly have long-term financial and economic implications affecting many people negatively in the future.

Beyond the above-mentioned, more general harms of lockdowns, they affect specific vulnerable groups particularly severely, in particularly those who rely more than others on personal contact, the existence of some form of social life or interaction, or help from others, such as psychiatric patients, people with severe health problems more generally (who may have avoided or delayed treatment), care home inhabitants (as mentioned), prisoners, and homeless people.

The above list is not meant to be comprehensive. If a court were given the task to assess the proportionality of a lockdown, it would ultimately be the court's task to determine the severity of the restriction. But given that a court does not have the necessary empirical expertise to assess this issue, it would heavily rely on the submission of the respective government that imposed the lockdown and that would ordinarily be expected to have undertaken an assessment of its likely collateral damage - the severity of the restriction -, which it would have used for its own decision-making process. On the basis of the political and public discourse since the beginning of the pandemic, it would seem that such a comprehensive assessment has never been undertaken; ${ }^{13}$ in any case its results

${ }^{9}$ https://www.theguardian.com/society/2021/aug/11/revealed-englands-pandemic-crisis-of-child-abuse-neglectand-poverty?CMP $=$ Share iOSApp Other.

${ }_{10}$ https:// commonslibrary.parliament.uk/domestic-abuse-and-covid-19-a-year-into-the-pandemic/.

11 Jeremy Waldron, Torture, Terror, and Trade-Offs: Philosophy for the White House (Oxford University Press, 2010), 308 : 'Treatment may be described as inhuman if it fails in sensitivity to the most basic needs and rhythms of a human life: the need to sleep, to defecate or urinate, the need for daylight and exercise, and perhaps even the need for human company.'

12 Although it will have to be factored in that some of the economic damage may not result from the lockdowns but from the spread of the virus itself, which may lead, for example, to heightened anxiety, less spending, etc.

${ }^{13}$ For the U.K., see Yossi Nehushtan, 'The British Lockdown is Disproportionate', IACL-AIDC Blog, April 9, 2020, available at https://blog-iacl-aidc.org/2020-posts/2020/4/9/the-british-lockdown-is-disproportionate: 
do not seem to have been communicated to the public. Nor was there much public discussion about the harms of lockdowns, for example in the media. Rather, the focus both on the part of the governments as well as the public was continually on the other side of the balance, namely on questions such as the Sars-Cov-2 incidence, hospitalisations, death rates, long Covid, etc. This created an imbalanced picture which will have led many to believe that the protection of people from the virus was the only relevant factor in assessing the justification and proportionality of lockdowns.

Needless to say, in the spring of 2020, with no prior experience of lockdowns in the liberal democratic world, the harms of lockdowns might have been very difficult to predict and there was a great urgency at the time. This, however, does not imply that no attempt to determine them was even necessary. Unless we have some, however uncertain and provisional, understanding of the effects of a proposed lockdown on people's freedom to live their lives, we cannot assess whether their benefits outweigh the harms. This applies even more obviously to the further lockdowns imposed in the autumn and winter of $2020 / 21$, by which time the governments surely had had enough time to prepare a comprehensive assessment.

\section{b. The importance of the public interest}

The second question at the balancing stage is the importance of the public interest, that is, the importance of protecting people's health and lives. Indisputably this is an issue of great public interest that could potentially justify severe measures. There was no shortage of models to calculate the number of people likely to die or develop long Covid if lockdowns were not imposed. But the problem with the public and political discussion of this issue was that a taboo was quickly placed on one of the crucially important questions: the relevance of the age distribution of the people dying of Covid. Thus, it became publicly and politically impossible to openly and freely discuss whether the fact that the average age of people dying of Covid was in the low 80s was relevant in deciding what measures were justified. The reason given for this was that all lives were equally valuable and entitled to the same protection. ${ }^{14}$

No comprehensive research has been invited by the government and no risk-assessment report has been prepared regarding the deaths, loss of life-quality, harm to people's social and mental well-being, and harm to the social fabric of society that will be caused as a result of an almost complete shutdown of UK economy and non-vital services for more than a few weeks.'; see further Jonathan Sumption, 'Government by decree: Covid-19 and the Constitution', available at https://resources.law.cam.ac.uk/privatelaw/Freshfields Lecture 2020 Government by Decree.pdf, p. 13: The Public Accounts Committee of the House of Commons reported in July that the lockdown was announced without any kind of cost-benefit analysis or advance planning for its disruptive economic effects. The many relevant social and educational considerations were disregarded in favour of an exclusive concentration on public health issues and only some of those.'

${ }^{14}$ In Germany, the issue was raised by the well-known mayor of Tübingen, Boris Palmer (Green party), who commented in a TV interview in April 2020: 'I will just state it brutally. In Germany, we are possibly saving people who would be dead in half a year anyway - because of their age or their pre-existing conditions.' (my translation); see https://www.tagesspiegel.de/politik/boris-palmer-provoziert-in-coronavirus-krise-wir-rettenmoeglicherweise-menschen-die-in-einem-halben-jahr-sowieso-tot-waeren/25782926.html. While Palmer's language is insensitive, his comment could, however, have been the beginning of an important conversation. Instead, it turned out to be its end. 
It seems to me that the age question is clearly a relevant consideration in deciding about the justifiability of lockdowns. To demonstrate this point, let us look at the following example. Imagine that you come to a lake and discover that two people have fallen into it and are about to drown. They are in different parts of the lake and you can only reach and save one of them in time. One of the two is 20 years old, and the other 90 . Under the approach that was promoted during the Covid crisis, the age of the person should be irrelevant because the lives of all people are equally valuable, and all people are entitled to the same protection. But I think it is quite obvious that in the example, the 20 year old should be saved. Why is this so? One answer might be that what matters is the remaining life span: since it is likely that the 20 -year-old will have much longer to live than the 90 year-old, he is the one to be saved. ${ }^{15} \mathrm{I}$ believe that this is not entirely correct. To demonstrate this, imagine the same scenario, but you know one additional piece of information, namely that the 90 -year-old, if saved, would enjoy five more years of life before dying of old age, whereas the 20 -year-old has incurable cancer and would also live for five more years if saved, before dying of his illness. I believe that in this case, again, the 20-year-old should be saved. The reason is that he has had less opportunity to live a full life than the 90-year-old. Other things being equal, the more of a full life a person has lived, the less urgent it becomes to save his life. This is also reflected in the insight that it is sad when someone close to us dies of old age but tragic when a young person dies.

These reflections support the view that the age of the average Covid death matters. One final illustration. Let us imagine that the next pandemic that hits mankind will kill overwhelmingly young adults (as the Spanish flu did). It seems to me that a virus that kills young people justifies stricter measures, including stricter lockdowns, than an otherwise equally dangerous virus that however kills mostly very old people. Again, the reason is not that young people's lives are 'worth more' than old people's lives, but rather reflects the simple fact that the older a person is, the closer they have come to living a full life.

Now, the fact that older people are entitled to less protection than younger people in this regard does not imply, of course, that lockdowns to protect mostly older people are disproportionate. The average age of the people dying of Covid-19 is just one consideration among many, and it may well turn out that the Covid lockdowns were justified despite the fact that the average age of the people dying of Covid was in the low 80s. But it is a relevant consideration that needs to be considered in the proportionality assessment. The misguided insistence that age is irrelevant distorts the normative picture that needs to be developed at the balancing stage of the proportionality test.

\section{c. Relating the severity of the restriction to the importance of the public interest}

The third and final task at the balancing stage requires placing the benefits and harms of lockdowns into a relation with each other. So we have to ask whether the harms of lockdowns, once they have been established as precisely as possible, are justified in light of the protection that lockdowns offer to the health and lives of mostly older people.

\footnotetext{
15 See Yossi Nehushtan (above n 13): 'Life has an expiry date. Therefore, it can never be 'saved' but rather prolonged; death cannot be avoided, only postponed.'
} 
Two ideas featured in the public and political discussions of this topic. The first, which I observed particularly in the German public discourse at the time, is that because of the high importance to be attached to the value of human life, the protection of life must always or usually take precedence over conflicting considerations. The second, which was relied on in the U.K., Germany, and other places, is that the balance between freedom and protecting lives must be struck such that the health care system must not be overburdened. Both approaches are unconvincing and ultimately suffer from the same deficiency: while they present their proposed solution as the outcome of a balancing exercise, in reality they do not engage in balancing at all and instead give categorical preference to one consideration over all others.

Let us first consider the idea that the protection of life always or virtually always outweighs other considerations. The implicit claim here is that it is not necessary to specify the harms of lockdowns because virtually any level of harm will be outweighed by the need to protect lives. This argument fails on a number of grounds.

First, it is not a principle that we have accepted in other parts of life. Thousands of people in the U.K. and elsewhere die of the flu every year, and until recently, this was not even considered newsworthy, let alone was it regarded as justifying even the mildest measures such as making it compulsory to wear face masks on public transport. Another example is that we allow driving even though this leads to innocent people, including children, dying without any fault of their own. The bottom line is that we tolerate a certain level of risk in the pursuit of going about our lives, even if this leads to innocent people dying. This means that in practice, we balance what we might call 'being physically alive' ('life') against 'living one's life' ('freedom'), and we do not give automatic priority to the protection of physical life over living one's life.

This is also normatively appropriate and is captured in the saying 'A ship is safe in harbour, but that's not what ships are built for'. Just as the point of having a ship is to use it for its purpose - transport of goods or people over water - even though this creates risks for the continued existence of the ship, the point of being physically alive is to live one's life, even though living one's life inevitably creates risks for one's health and survival. Societies develop certain levels of risk to physical life that they are willing to tolerate in the name of protecting people's ability to live their lives.

It is therefore a mistake to give categorical preference to 'physical life' ('life') over 'living one's life' ('freedom'). This applies even to restrictions on freedom that many rightly or wrongly consider as trivial, such as mask mandates. Imagine that imposing a national mask mandate in the U.K. would lead to five fewer persons dying per year. Under the logic that life takes precedence over the avoidance of trivial restrictions, such a mandate would be justified and might indeed be obligatory. But quite obviously, in this case such a mandate would be disproportionate. The lesson is that a small burden imposed on many people may outweigh a grave burden on the few. Thus, what matters for striking the balance between life and freedom is not only, qualitatively, the importance of the respective values but also, quantitatively, the number of people affected.

It follows that the idea that protecting lives takes precedence over other considerations is wrong and what is instead necessary is what the proportionality test instructs us to do, namely to balance the need to protect lives against the importance of 
maintaining as much freedom as possible, rather than giving unconditional priority to one of these values.

Perhaps the more plausible interpretation of the idea that life takes precedence over conflicting considerations is that while life does not take automatic preference over other considerations, in the case of the Covid-19 pandemic, even a cursory glance at the costs and benefits of lockdowns made it clear that lockdowns were justified. Thus, the argument goes that we do not need an in-depth investigation of the benefits and costs of lockdowns to conclude that at least in this particular instance they were justified. It is true that we often and inevitably make intuitive judgments that involve striking a balance between competing considerations. ${ }^{16}$ Perhaps the balance between the pros and cons of lockdowns was so clearly on the side of lockdowns during the relevant stages of the Covid pandemic that there simply was no question about their justifiability.

But this argument does not strike me as convincing, either. While it is certainly true that the Covid-19 pandemic posed a risk to health and/or life of many people and that the number of people falling ill and dying was presumably considerably reduced by the lockdowns, it is also clear that lockdowns are, first, extremely severe restrictions on freedom, as evidenced by the fact that presumably for most of us, even those who were not in a position of particular vulnerability, they were by far the most severe restrictions on freedom that we have experienced in our lifetimes, and, second, that they affected literally everyone. So both in terms of the quality of the restriction and in terms of the quantity of people affected, they stand out as extreme. In light of this, we simply cannot make the judgment that they are justified unless we have some grasp of their consequences for people's ability to live their lives, and then engage in a proper balancing exercise.

To make the point in a different way, it may have seemed that the prospect of many more people dying of Covid than absolutely necessary was so awful that this situation simply had to be avoided. I agree that this outlook was awful, but proportionality as well as common sense instruct us to assess whether the cure might be worse than the disease. The sad truth is that the Covid-19 pandemic presented us with a moral dilemma, in that there was no 'good' option available to states. All possible courses of action, ranging from letting the virus rip through society to the strictest of lockdowns would have resulted in grave harm. The task for states in this position was to balance the relevant considerations and find the solution which leads to the least harm overall, whereas what seems to have happened is that faced with the possibility of large additional numbers of people dying, public and political discourse decided to largely ignore the harms of lockdowns in their deliberations.

The second argument relied on by states in justifying lockdowns is that it was necessary to prevent the health care system from being overburdened. The best interpretation of this idea seems to me to be that protecting life does not necessarily trump all other considerations, but that the balance between 'life' and 'freedom' must be struck such that it must be ensured that medical treatment will be available for everyone who needs it.

16 Kai Möller, 'Proportionality: Challenging the Critics', 10 (2012) International Journal of Constitutional Law 709, 728 730. 
But this argument is unconvincing. First, and more as a preliminary point, it seems plausible to assume that for economic reasons, hospital capacities are designed such that hospitals will regularly - say, during winter, when more people fall ill - be near or at capacity. This means that even a relatively small increase in admissions (for example because of a pandemic) could overburden the health service; under the approach examined here, this would then justify drastic lockdowns, irrespective of their possibly very severe side effects. This cannot be right.

Second, it is not clear why the protection of the health service should be given priority over all other considerations. The idea is certainly psychologically understandable to some extent: it is comforting to know that if one catches the virus and becomes severely ill, treatment will be available. Surely the mere thought of being severely ill and being denied treatment that could save one's life is terrifying. But apart from appealing to an anxiety that many will share, the harsh reality is that there are many other terrible things that can and do happen to people, in normal times and even more so during pandemics and lockdowns. It is simply not clear why the avoidance of this particular evil (hospitals being overburdened) should be prioritised over all others, including, for example, the avoidance of the evil of inflicting considerable developmental damage or trauma on children that will presumably burden many of them for the rest of their lives.

The argument regarding the need to prevent the health services from being overburdened and the argument regarding giving preference to protecting lives over other considerations both suffer from the same flaw. They elevate one, certainly relevant and important, consideration from a principle that has to be balanced with all other principles to the status of an absolute rule. ${ }^{17}$ Thus, these approaches do not do what proportionality and common sense instruct us to do, namely to balance all relevant considerations, taking into account both the importance of the values at stake and the number of people affected. Rather, they unjustifiably give preference to just one of the many relevant considerations.

It seems, then, that the existing arguments about striking the balance were flawed. How should the balance have been struck? I do not know the answer to that difficult question. My goal in this paper is not primarily to make new proposals about how to deal with pandemics but more to assess the plausibility of the arguments relied on in the public and political discourse about lockdowns. There is no doubt that striking the appropriate balance between 'saving lives' and maintaining a state of 'normal freedom' is extremely difficult. Resolving it requires much more than one academic coming up with a proposal, namely a collaborative effort that is best carried out by way of open public debate among politicians, the media, academic experts in a broad range of disciplines, and the citizenry at large. My criticism of the existing discourse is that the one-sidedness and narrowness of the existing debates did not allow for the potential of such a discourse to be realised. 17 On the distinction between principles ('optimisation requirements') and rules ('fixed points'), see Alexy (above $\mathrm{n}$
7), ch. 3 . 


\section{CONCLUSION}

The fact that after one and a half years of intense focus on the Covid 19 pandemic, this paper and its author reach the conclusion that it is not yet possible to answer the question about the proportionality of the recent lockdowns is, if correct, itself a cause for concern. Remember that proportionality is not a technical legal doctrine that has little bearing on important issues in the real world. On the contrary, proportionality is a structure that guides judges through the process of reasoning whether repressive state measures are justifiable. The considerations that judges rely on when applying proportionality are, by and large, the same as those that citizens, journalists, and politicians rely on when assessing the morality or appropriateness of such measures. The question of the proportionality of lockdowns is at the very core of the assessment of their moral, legal, and constitutional legitimacy. The fact that after a long period of time in which the pandemic dominated the media, public and political discourse, and virtually everyone's thinking to an unprecedented extent, we still have no answers to some of the basic, crucial questions concerning the legitimacy of the course of action chosen by large parts of the world, points to a weakness in our democratic culture.

One can certainly regret the political polarisation in the United States, with its hysterical shouting, absence of genuine argument ${ }^{18}$ as well as the willingness to compromise, and the presence of (usually two) conflicting narratives even in situations when all democrats should agree on one interpretation of the world or one course of action. But at least with regard to the Covid-19 pandemic, Europe, or at least the United Kingdom and Germany (as the two countries whose public and political discourse I have followed closely), have suffered from the opposite problem. It cannot be right if on a question as new, difficult, and unresolved as the question about the proper response to the Covid-19 pandemic, and in a situation that is novel, fluctuating, and unpredictable, only one course of action - the lockdown-endorsing one - is admitted to the realm of respectable public discourse. A mature democracy will actively discuss more than just one course of action in such circumstances. To be fair, the respective ideas whose far-reaching absence in public discourse I bemoan in this chapter - thinking more about the costs of lockdowns to freedom, questioning the relevance of the average age of the people dying of Covid, and questioning the preference given to the protection of life over other considerations - were all at some point considered and discussed. But they were rejected too quickly and eradicated from the realm of respectability too fiercely, leaving the lockdown-endorsing strategy as the only acceptable one and pushing the discussion of alternatives into the private spheres. Citizens in a mature democracy have to insist that alternative strategies to the one chosen by their leaders are openly and comprehensively discussed even in the face of the anxiety and hysteria which a pandemic with a new, invisible, and in many cases lethal threat brings about. In the present context, this is not

18 As bemoaned, for example, by Ronald Dworkin, Is Democracy Possible Here? Principles for a New Political Debate (Princeton University Press, 2006), 4-5, with regard to the 2004 presidential election: 'I mean "argument" in the old-fashioned sense in which people who share some common ground in very basic political principles debate about which concrete policies better reflect these shared principles. There was none of that argument in the formal election rhetoric of the last presidential election...' 
primarily a matter of free speech but rather of instrumental value for reaching proportionate and therefore justifiable and constitutionally legitimate policies. If that necessary discourse had happened, as it should have in mature democracies, we would now have better answers to the question of the proportionality of lockdowns. 